\title{
Sedentary behavior as a public health issue: Ergonomics as a useful tool
}

\author{
Senad Burak ${ }^{1 *}$, Edin Begic ${ }^{2,3}$, Nedim Begic $^{4}$, Faris Kadic $^{5}$ \\ ${ }^{1}$ Faculty of Mechanical Engineering, University of Sarajevo, Sarajevo, Bosnia \\ 2 Department of Cardiology, General Hospital „Prim.dr. Abdulah Nakas“, Sarajevo, Bosnia \\ ${ }^{3}$ Department of Pharmacology, School of Medicine, Sarajevo School of Science and Technology, Sarajevo, Bosnia \\ ${ }^{4}$ Pediatric Clinic, Clinical Center University of Sarajevo, Sarajevo, Sarajevo, Bosnia \\ ${ }^{5}$ Health Care Centre Sarajevo, Sarajevo, Bosnia
}

*Corresponding author: burak@mef.unsa.ba

\section{(C) The Author}

2019.

Published by

ARDA.

\begin{abstract}
Background: Sedentary behavior carries the risk of musculoskeletal problems, especially in the lumbosacral region of the spinal column. According to modern lifestyle, this has begun to be a public health issue.

Objective: To point to the health risks of working at the computer and present an ergonomic analysis of the typical and improved position of workers in front of the computer, thereby reducing the chances of emergence occupational diseases.

Results: Changing the position of the subjects led to a change in lumbar pressure from $2,818 \mathrm{~N} / \mathrm{m} 2$ to $351 \mathrm{~N} / \mathrm{m} 2$. Software analysis of the changed position indicates that this position is acceptable, both for the lumbosacral region of the spine and for the abdominal muscles.

Conclusions: A change in body position will decrease lumbar moment and the load on the lumbosacral region of the spine. Work chair with lumbar support, the right desk height, setting the appropriate position of the monitor, selecting the optimal keyboard and mouse, dividing the workspace into appropriate zones, as well as changing lifestyle and habits should be part of the management of people who spend most of their working time in a sitting position.
\end{abstract}

Keywords: Ergonomics, Sitting position, Prevention, Software

\section{Preparation}

Occupational diseases caused by inappropriate working position of the body present one of the biggest problems of modern medical practice. It is estimated that up to $60 \%$ of the population suffer from low back pain, with many cases directly related to inadequate posture or poor seat design. Spending 8 to 15 hours a day in sitting position is related to back and neck pain [1]. Practice shows that among people who have acute lower back pain, in up to $30 \%$ they will develop chronic pain [1]. Pain in the lumbosacral region of spine is divided into acute, subacute (4 to 12 weeks) and chronic (duration more than 12 weeks) type [1]. Spine sprains and strains are the most common cause of acute pain. In addition, intervertebral disc degeneration, disc herniation or rupture, spondylolisthesis, radiculopathy, pathological changes in the musculoskeletal system, along with spinal canal stenosis or trauma present other causes of acute pain. The prevalence of chronic pain in the lumbosacral part of the spine has increased over $100 \%$ in the last decade, and this trend is projected to

This work is licensed under a Creative Commons Attribution License (https://creativecommons.org/licenses/by/4.0/ ) that allows others to share and adapt the material for any purpose (even commercially), in any medium with an acknowledgement of the work's authorship and initial publication in this journal. 
continue to grow [1,2]. In 95\% of cases, the problem lies in the involvement of the spinal roots (L4-L5, L5$\mathrm{S} 1$ ). The risk of back pain is related to age, profession (focus is placed on professions in which people are in seated position because that carries the risk of developing disc damage and back pain), as well as body posture. Body posture pathology can have anatomical and functional causes. Working position and inadequate lifestyle lead to changes in the musculoskeletal system, which affects not only the health of individuals but also the quality of the work process. Given that obesity is most often accompanied by a sedentary lifestyle, the presence of obesity further complicates this problem.

Musculoskeletal pathology or musculoskeletal disorders are one of the biggest problems in the working population, and the most common cause of disability [3,4]. Musculoskeletal disorders most commonly occur in workers who have excessive repetition, awkward postures and heavy lifting [5]. The modern world and modern businesses have are most often done in sitting position [6]. Office workers are in a sitting position for about two-thirds of their working hours [7]. Daneshmandi et al. state that neck, lower back and shoulder symptoms were the most prevalent problem among office workers [7]. The increasing occurrence of these problems in modern man has led to the development of the term sedentary behavior, which is a public health issue [8]. Sedentary behavior is defined behavior in which no more than 2 Metabolic Equivalent Tasks (METs) are spent [9]. Although this definition is subject to variation, this behavior is essentially a behavior that does not lead to excessive consumption of metabolic energy. It presents a risk factor for the individual, and prevention with physical activity can have a positive effect on the quality of life (physical, psychological and social health and the overall health of an individual) [10]. Pronk et al. stated that prolonged sitting is associated with a higher risk of premature mortality, chronic diseases such as cardiovascular disease, diabetes mellitus, cancer, metabolic syndrome and obesity [11]. It is necessary to take into account the ergonomic principles when designing a workplace with a computer, thus realizing the humanization of work, and poorly designed ergonomics for computers is one of the most significant causes of musculoskeletal problems [12]. The working position must allow the position to be changed within the limits to which the worker redistributes the mass during work, without changing his general working position. Musculoskeletal symptoms have been shown to be associated with prolonged use of the computer, but the real prevalence is very difficult to assess because often these symptoms are unreported [12]

Considering that these problems recur from day to day, for a longer period of time, and are treated symptomatically, most often by analgesics. This lifestyle and this occupational disease lead to musculoskeletal disorders and the onset of chronic pain, which is difficult for occupational medical treatment, and present also a problem for the organization itself and for the individuals who are unable to perform business activities. Prevention of health problems begins in an adequate working environment as well as ergonomic redesign of chairs in desks, with the recommended ergonomic principles, adequate position of the body, intermittent physical activity during working hours and with adequate diet and exercise, along with outside working activities. It is imperative to emphasize that the prevention of chronic pain and lumbosacral syndrome is based on the correction of postural problems, which emphasize new ergonomic solutions that should have gain its place in the everyday working community.

\section{Aim}

To present the ergonomic analysis of the office worker's workplace while working in front of a computer screen and to determine solution for improving working conditions and prevention of musculoskeletal disorders.

\section{Methods}

Article presents an ergonomic analysis performed in the CATIA software package (Dassault Systèmes, Vélizy-Villacoublay, France). In research, The RULA Assessment Tool was used to analyze and interpret proposed solution (score 1-2 -green color - negligible risk, no action required; score 3-4 - light yellow - low 
risk, change may be needed; score 5-6 - yellow - medium risk, change soon; score> 6 - red color - very high risk, implement change needed).

\section{Results}

In order to analyze the load in the lumbar region during raising and lowering the patient, a nurse model of body weight $62 \mathrm{~kg}$, height $170 \mathrm{~cm}$ and 30 years of age was created (Fig. 1). A patient that is lifted from the wheelchair of $50 \mathrm{~cm}$ in height was modeled to be $70 \mathrm{~kg}$ of body weight, as shown in Fig. 2 .

\subsection{Biomechanical analysis}

Using the CATIA V5 - R18 software (Dassault Systèmes, Vélizy-Villacoublay, France), an appropriate model was designed. The basic characteristics of an office worker are: female, age 35, height $168 \mathrm{~cm}$ and weight 75 $\mathrm{kg}$. The typical, but apparently disadvantageous working position, shown in Fig. 1, was analyzed in CATIA biomechanical module and RULA analysis.
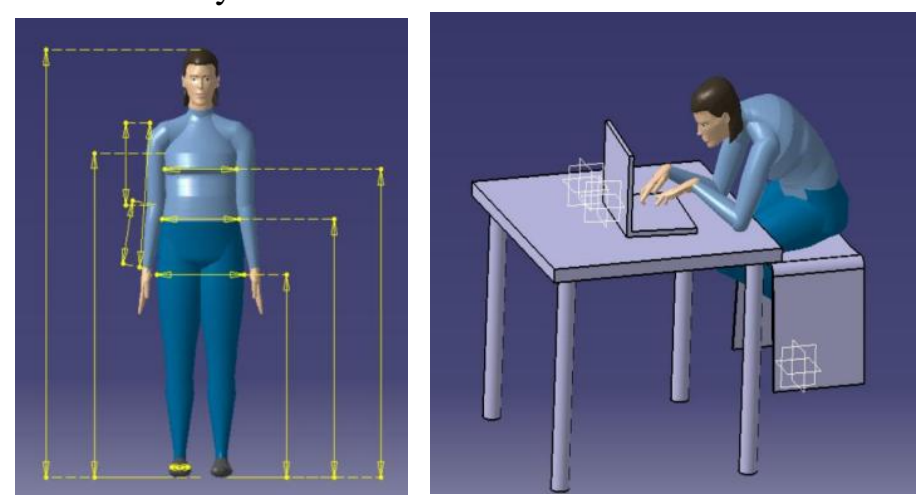

Figure 1. CATIA computer model and typical body position of the worker

\begin{tabular}{|c|c|c|c|c|c|}
\hline Segment & Proximal force [N_... & Distal Force [N_m2] & Proximal Moment -.. & Distal Moment [kg] & ] Fig. 2. (a) \\
\hline \multicolumn{6}{|c|}{ 然 } \\
\hline $\mathrm{x}$ & 0 & 0 & 0 & 0 & \\
\hline r & 0 & 0 & 4 & 0 & \\
\hline$z$ & 15 & -4 & 0 & 0 & \\
\hline \multicolumn{6}{|l|}{ Right Arm } \\
\hline$\ddot{x}$ & 0 & 0 & -1 & 0 & \\
\hline Y & 0 & 0 & 8 & -4 & \\
\hline$z$ & 37 & -15 & 0 & 0 & \\
\hline \multicolumn{6}{|l|}{ Left Hand } \\
\hline $\mathrm{x}$ & 0 & 0 & 0 & 0 & \\
\hline$\gamma$ & 0 & 0 & 0 & 0 & \\
\hline$z$ & 4 & 0 & 0 & 0 & \\
\hline \multicolumn{6}{|c|}{ Left Forearm } \\
\hline$x$ & 0 & 0 & -3 & 0 & \\
\hline Y & 0 & 0 & 2 & 0 & 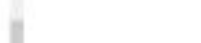 \\
\hline$z$ & 15 & -4 & 0 & 0 & \\
\hline \multicolumn{6}{|l|}{ Left Arm } \\
\hline $\mathrm{x}$ & 0 & 0 & -1 & 3 & \\
\hline Y & 0 & 0 & 8 & -2 & \\
\hline$z$ & 37 & -15 & 0 & 0 & \\
\hline \multicolumn{6}{|c|}{ Head-Neck } \\
\hline$x$ & 0 & 0 & 0 & 0 & \\
\hline Y & 0 & 0 & 11 & 0 & \\
\hline$z$ & 57 & 0 & 0 & 0 & \\
\hline \multicolumn{6}{|l|}{ Pelvis } \\
\hline$x$ & 0 & 0 & -2 & 2 & \\
\hline$\gamma$ & 0 & 0 & 164 & -155 & \\
\hline$z$ & 480 & -372 & 0 & 0 & \\
\hline \multicolumn{6}{|l|}{ Trunk } \\
\hline$x$ & 0 & 0 & -2 & 2 & \\
\hline Y & 0 & 0 & 155 & -20 & \\
\hline$z$ & 372 & -132 & 0 & 0 & ? \\
\hline
\end{tabular}




\begin{tabular}{|l|l|l|l|l|l|}
\hline Segment & Proximal Coordinates $[\mathrm{N}]$ & Distal Coordinates $[\mathrm{N}]$ & $X Z$ plane... & YZ plane... & Center of gr \\
\hline Right Foot & $(0.049,-0.087,-0.320)$ & $(0.072,-0.087,-0.445)$ & -1.4 & -1.6 & $(0.061,-0.08$ \\
Right Leg & $(0.413,-0.087,-0.124)$ & $(0.049,-0.087,-0.320)$ & -2.6 & -1.6 & $(0.256,-0.08$ \\
Right Thigh & $(0.000,-0.087,0.000)$ & $(\mathrm{N}) .413,-0.087,-0.124)$ & -0.3 & -1.6 & $(0.179,-0.08$ \\
Left Foot & $(0.063,0.087,-0.359)$ & $(0.096,0.087,-0.481)$ & -1.3 & -1.6 & $(0.079,0.087$ \\
Left Leg & $(0.410,0.087,-0.135)$ & $(0.063,0.087,-0.359)$ & -2.6 & -1.6 & $(0.260,0.087$ \\
Left Thigh & $(0.000,0.087,0.000)$ & $(0.410,0.087,-0.135)$ & -0.3 & -1.6 & $(0.178,0.087$ \\
Right Hand & $(0.592,-0.175,0.117)$ & $(0.672,-0.149,0.074)$ & -0.5 & -2.1 & $(0.632,-0.16$ \\
Right Forearm & $(0.362,-0.166,0.013)$ & $(0.592,-0.175,0.117)$ & 0.4 & 1.5 & $(0.461,-0.17$ \\
Right Arm & $(0.260,-0.134,0.275)$ & $(0.362,-0.166,0.013)$ & -1.2 & -1.4 & $(0.304,-0.14$ \\
Left Hand & $(0.530,-0.006,0.117)$ & $(0.612,-0.038,0.082)$ & -0.4 & -0.8 & $(0.571,-0.02$ \\
Left Forearm & $(0.392,0.186,0.030)$ & $(0.530,-0.006,0.117)$ & 0.6 & 0.4 & $(0.451,0.104$ \\
Left Arm & $(0.260,0.134,0.275)$ & $(0.392,0.186,0.030)$ & -1.1 & -1.8 & $(0.318,0.157$ \\
Head-Neck & $(0.348,0.000,0.346)$ & $(0.446,0.000,0.391)$ & 0.4 & 1.6 & $(0.446,0.000$ \\
Pelvis & $(0.000,0.000,0.000)$ & $(0.016,0.000,0.128)$ & 1.4 & 1.6 & $(0.006,0.00 C$ \\
Trunk & $(0.016,0.000,0.128)$ & $(0.348,0.000,0.346)$ & 0.6 & 1.6 & $(0.164,0.000$ \\
\hline
\end{tabular}

Figure 2. Biomechanical analysis of the typical body position: (a) Reaction forces and moments; (b) Segment positions

\begin{tabular}{|l|l|}
\hline Analysis & Value \\
\hline L4-L5 Moment [kg] & 155 \\
& 2818 \\
L4-L5 Compression [N_m2] & 204 \\
Body Load Compression [N_m2] & 14 \\
Axial Twist Compression [N_m2] & 2576 \\
Flex/Ext Compression [N_m2] & \\
& 85 Anterior \\
L4-L5 Joint Shear [N_m2] & 95 \\
& 3 \\
Abdominal Force [N_m2] & \\
Abdominal Pressure [s] & \\
& 0 \\
Ground Reaction [N_m2] & 0 \\
Total $(X)$ & 736 \\
Total $(\mathrm{Y})$ & \\
Total $(\mathrm{Z})$ & 0 \\
Left Foot $(X)$ & 0 \\
Left Foot $(\mathrm{Y})$ & 729 \\
Left Foot $(\mathrm{Z})$ & \\
& 0 \\
Right Foot $(X)$ & 0 \\
Right Foot $(\mathrm{V})$ & 7 \\
Right Foot $(\mathrm{Z})$ & \\
&
\end{tabular}

Figure 3. Summary of the biomechnical analysis the typical body position

To calculate the biomechanical stress of the worker, the lumbar spine (the disc between the 4th and 5th lumbar vertebra - point L4/L5) is taken as the critical body size. Studies have shown [13] that intra-abdominal pressure increases depending on the increase in lumbar momentum, the magnitude of which can be expressed by the regression equation:

$$
p_{a b d}=I A T=0.079 * M_{L}-1.127[\mathrm{kPa}]
$$

with the regression correlation coefficient of $r=0.7$.

Taking into account the result of biomechanical analysis of the typical body position which showed that the moment in the lumbar zone $\mathrm{L} 4 / \mathrm{L} 5 \mathrm{ML}=155 \mathrm{~kg}$, we obtain that

$$
p_{a b d}=0.079 * 155-1.127=11.118[\mathrm{kPa}]
$$


The calculated value of abdominal load can be used as an index of spinal load in actual working conditions. In this case, this value is extremely unfavorable for the worker, especially in cases of prolonged exposure to the said load. Due to the unfavorable position of the body and the stated intensity of the load, the corresponding reactions occur both in the muscles and the skeletal system, and especially in the abdominal space, which responds with an increase or decrease in internal pressure. This pressure acts upward on the diaphragm, and downward on the bottom of the pelvis, while forward it acts on the abdominal muscles and on the back on the spine and lumbar muscles. The calculated lumbar torque value can be used to determine the appropriate reactive force in the abdominal cavity.

\subsection{RULA Analysis}

A RULA analysis was performed for the specified worker position (Fig. 4).

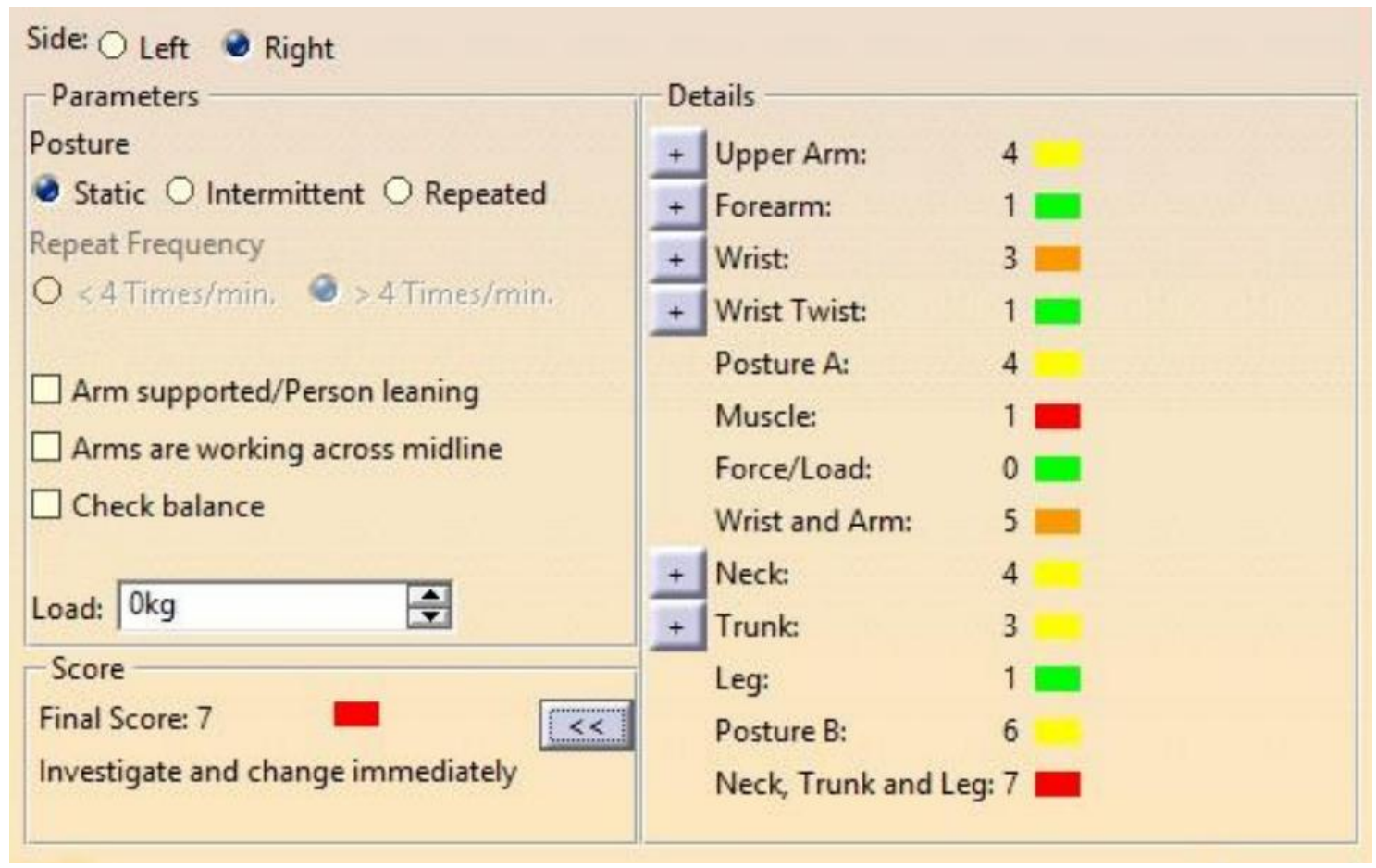

Figure 4. RULA analysis of the typical body position

We note that the result of the RULA analysis for this position is unfavorable to the worker, with the Final Score of 7 (red color) and the message 'Investigate and change immediately'.

\subsection{Redesigned workspace}

There are a number of ways we can improve work postures like this. We can make these improvements based on the results of the mechanical load obtained for the previously mentioned work position, all with the aim of keeping the worker in the most convenient position. We also aim to increase worker productivity, which increases productivity for the entire company. However, under the real conditions that prevail for such a workplace, the most appropriate solution to relieve workers is to improve body posture and move the target muscle groups instead of the muscles individually. In this regard, 6 steps are recommended that contribute to an improved position at work, that is, to reduce the burden on workers. These include: selecting the right ergonomically friendly work chair with lubmar support, selecting the right work desk height $(73 \mathrm{~cm}+/-2.5$ $\mathrm{cm}$ ), setting the appropriate position of the monitor (at angle of 10-20 degrees), selecting the optimal keyboard and mouse, division of work space into appropriate zones, as well as changing lifestyle and habits.

An example of a favorable and less damaging work position for workers, for which a load analysis was also made, is given in Figure 5. 

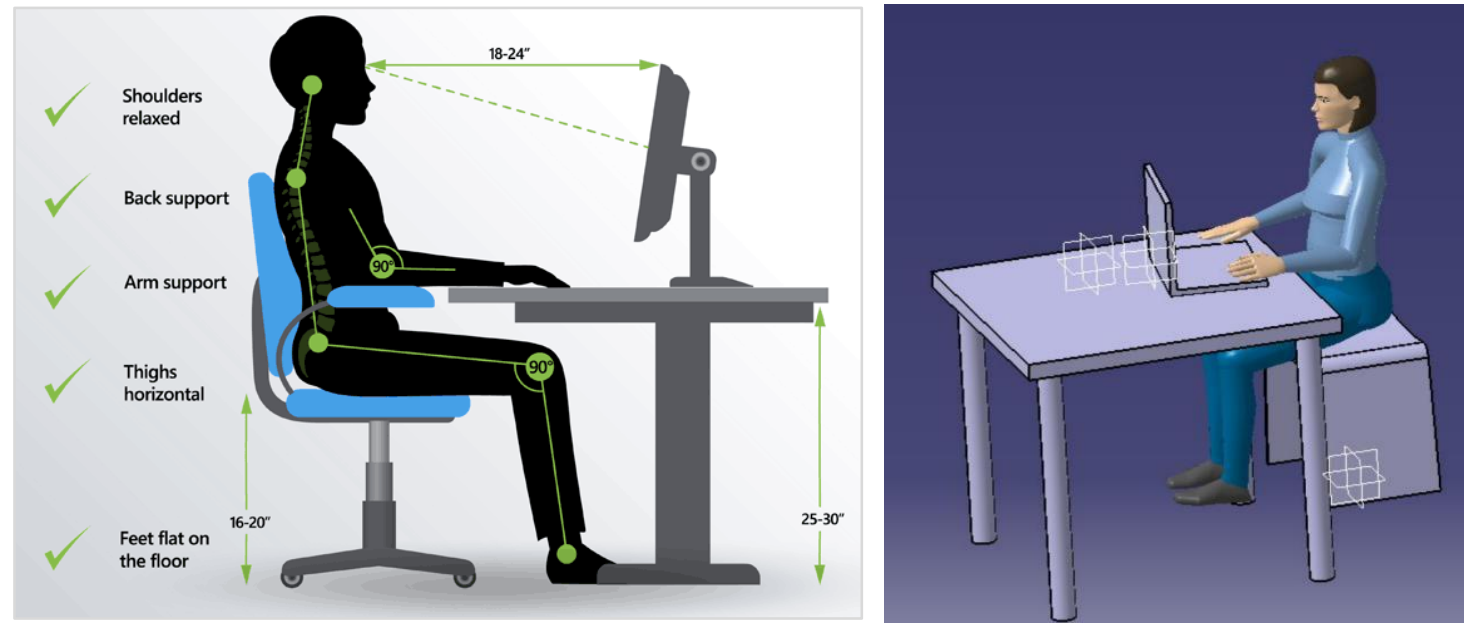

Figure 5. Optimized workspace and body position

\section{Biomechanical and RULA analysis of the improved body position}

Biomechanical and RULA analysis was performed for the advanced position of workers, whose results are shown in Fig. 6.

\begin{tabular}{|c|c|c|c|c|c|c|}
\hline Segment & Proximal Coordinates [N] & Distal Coordinates [N] & $X Z$ plane... & VZ plane... & Center of gravity coordinat... & Length $[\ldots$ \\
\hline Right Foot & $(0.416,-0.084,-0.508)$ & $(0.534,-0.084,-0.542)$ & -0.3 & -1.6 & $(0.475,-0.084,-0.525)$ & 0.123 \\
\hline Right Leg & $(0.402,-0.084,-0.110)$ & $(0.416,-0.084,-0.508)$ & -1.5 & -1.6 & $(0.408,-0.084,-0.282)$ & 0.398 \\
\hline Right Thigh & $(0.000,-0.084,0.000)$ & $(0.402,-0.084,-0.110)$ & -0.3 & -1.6 & $(0.174,-0.084,-0.048)$ & 0.417 \\
\hline Left Foot & $(0.434,0.084,-0.517)$ & $(0.554,0.084,-0.544)$ & -0.2 & -1.6 & $(0.494,0.084,-0.530)$ & 0.123 \\
\hline Left Leg & $(0.399,0.084,-0.120)$ & $(0.434,0.084,-0.517)$ & -1.5 & -1.6 & $(0.414,0.084,-0.292)$ & 0.398 \\
\hline Left Thigh & $(0.000,0.084,0.000)$ & $(0.399,0.084,-0.120)$ & -0.3 & -1.6 & $(0.173,0.084,-0.052)$ & 0.417 \\
\hline Right Hand & $(0.222,-0.243,0.193)$ & $(0.309,-0.263,0.178)$ & -0.2 & -0.6 & $(0.266,-0.253,0.185)$ & 0.091 \\
\hline Right Forearm & $(-0.009,-0.315,0.219)$ & $(0.222,-0.243,0.193)$ & -0.1 & -2.8 & $(0.090,-0.284,0.208)$ & 0.243 \\
\hline Right Arm & $(-0.019,-0.139,0.428)$ & $(-0.009,-0.315,0.219)$ & -1.5 & -0.9 & $(-0.015,-0.215,0.336)$ & 0.273 \\
\hline Left Hand & $(0.307,0.321,0.238)$ & $(0.396,0.339,0.250)$ & 0.1 & 2.6 & $(0.352,0.330,0.244)$ & 0.091 \\
\hline Left Forearm & $(0.073,0.265,0.208)$ & $(0.307,0.321,0.238)$ & 0.1 & 2.7 & $(0.174,0.289,0.221)$ & 0.243 \\
\hline Left Arm & $(-0.032,0.138,0.426)$ & $(0.073,0.265,0.208)$ & -1.1 & -2.1 & $(0.013,0.193,0.331)$ & 0.273 \\
\hline Head-Neck & $(-0.037,0.000,0.531)$ & $(-0.021,0.000,0.651)$ & 1.4 & 1.6 & $(-0.021,0.000,0.651)$ & 0.121 \\
\hline Pelvis & $(0.000,0.000,0.000)$ & $(0.006,0.000,0.129)$ & 1.5 & 1.6 & $(0.002,0.000,0.047)$ & 0.129 \\
\hline Trunk & $(0.006,0.000,0.129)$ & $(-0.037,0.000,0.531)$ & 1.7 & 1.6 & $(-0.016,0.000,0.269)$ & 0.404 \\
\hline
\end{tabular}

Fig. (a)

\begin{tabular}{|c|c|c|c|c|}
\hline Segment & Proximal Force $\left[\mathrm{N}_{-} . .\right.$. & Distal Force [N_m2] & Proximal Moment ... & Distal Moment \\
\hline \multicolumn{5}{|c|}{ 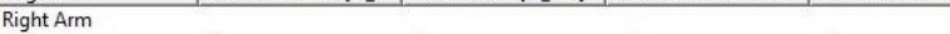 } \\
\hline$x$ & 0 & 0 & -5 & -1 \\
\hline$\gamma$ & 0 & 0 & 3 & -3 \\
\hline z & 31 & -12 & 0 & 0 \\
\hline \multicolumn{5}{|l|}{ Left Hand } \\
\hline $\mathrm{x}$ & 0 & 0 & 0 & 0 \\
\hline Y & 0 & 0 & 0 & 0 \\
\hline z & 3 & 0 & 0 & 0 \\
\hline \multicolumn{5}{|c|}{ Left Forearm } \\
\hline $\mathrm{x}$ & 0 & 0 & 1 & 0 \\
\hline Y & 0 & 0 & 3 & 0 \\
\hline z & 12 & -3 & 0 & 0 \\
\hline \multicolumn{5}{|l|}{ Left Arm } \\
\hline $\mathrm{x}$ & 0 & 0 & 5 & -1 \\
\hline$Y$ & 0 & 0 & 7 & -3 \\
\hline z & 31 & -12 & 0 & 0 \\
\hline \multicolumn{5}{|c|}{ Head-Neck } \\
\hline $\mathrm{x}$ & 0 & 0 & 0 & 0 \\
\hline r & 0 & 0 & 1 & 0 \\
\hline z & 47 & 0 & 0 & 0 \\
\hline \multicolumn{5}{|l|}{ Pelvis } \\
\hline $\mathrm{x}$ & 0 & 0 & 0 & 0 \\
\hline Y & 0 & 0 & -1 & 3 \\
\hline z & 397 & -307 & 0 & 0 \\
\hline \multicolumn{5}{|l|}{ Trunk } \\
\hline$x$ & 0 & 0 & 0 & 0 \\
\hline Y & 0 & 0 & -3 & -12 \\
\hline z & 307 & -109 & 0 & 0 \\
\hline
\end{tabular}

Fig. (b)

Figure 6. Biomechanical analysis of the improved body position: (a) Segment positions; (b) Reaction forces and moments 
As can be seen, the results of the analysis show a significant improvement in all segments. This is also reflected in the calculated torque in the L4-L5 zone, which is now significantly reduced from the previous position (Fig. 7).

\begin{tabular}{|l|l|}
\hline Analysis & Value \\
\hline L4-L5 Moment [kg] & -3 \\
& 351 \\
L4-L5 Compression [N_m2] & 306 \\
Body Load Compression [N_m2] & 0 \\
Axial Twist Compression [N_m2] & 40 \\
Flex/Ext Compression [N_m2] & 29 Posterior \\
L4-L5 Joint Shear [N_m2] & 0 \\
Abdominal Force [N_m2] & 0 \\
Abdominal Pressure [s] & \\
& 0 \\
Ground Reaction [N_m2] & 0 \\
Total $(X)$ & 608 \\
Total $(\mathrm{N})$ & 0 \\
Total $(\mathrm{Z})$ & 0 \\
Left Foot $(X)$ & -833 \\
Left Foot $(M)$ & 0 \\
Left Foot $(\mathrm{Z})$ & 0 \\
Right Foot $(X)$ & 1441 \\
Right Foot $(\mathrm{M})$ & \\
Right Foot $(\mathrm{Z})$ & \\
& \\
\hline
\end{tabular}

Figure 7. Summary of the biomechnical analysis of the improved body position

Considering the result of biomechanical analysis of the improved body position that I showed that momentum is in the lumbar area $\mathrm{L} 4 / \mathrm{L} 5, M_{L}=-3 \mathrm{~kg}$, we get

$$
p_{a b d}=0.079 *(-3)-1.127=-1.364[\mathrm{kPa}]
$$

The calculated value of the abdominal load is now substantially reduced and is fairly favorable for workers.

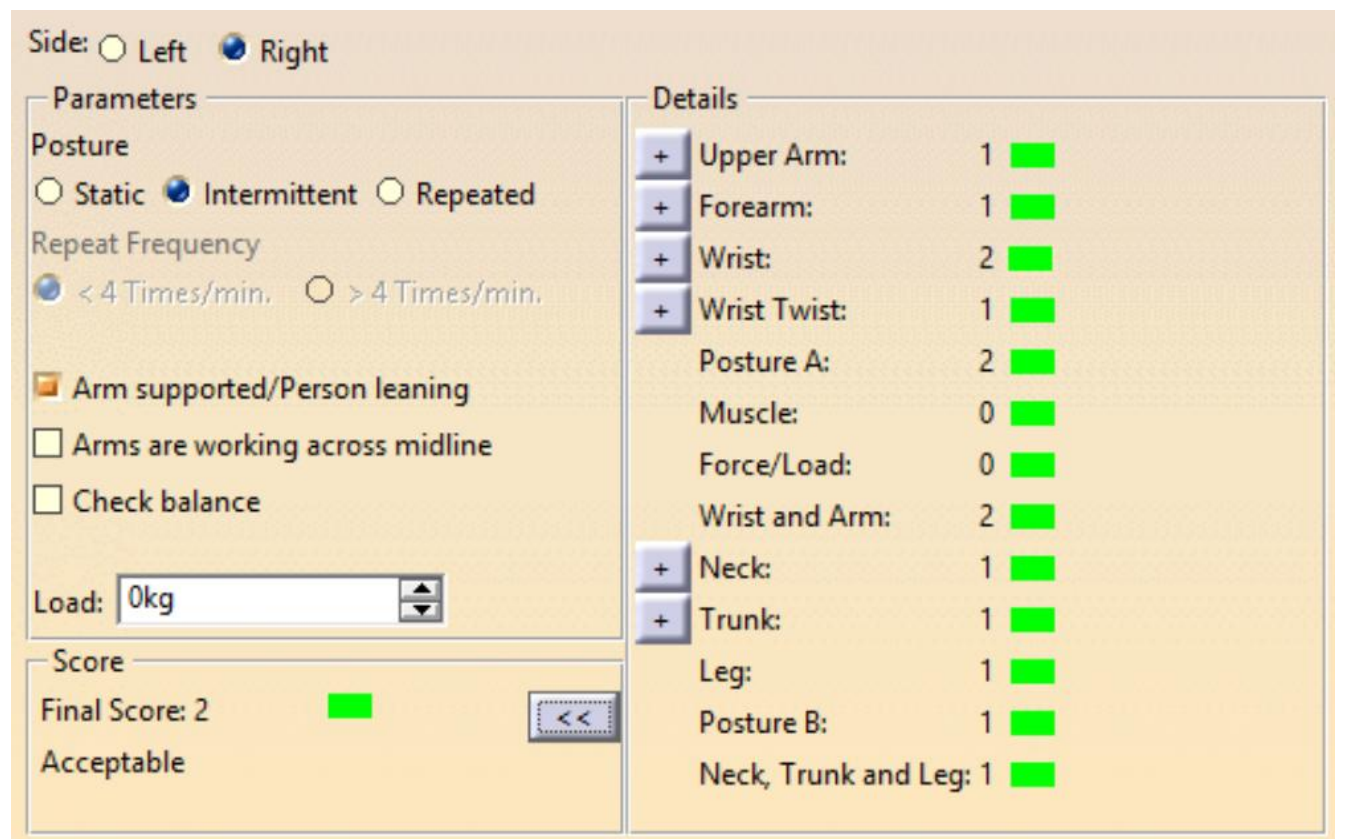

Figure 8. RULA analysis of the improved body position 
We note that the result of the RULA analysis for the improved body position is now favorable to the worker, with the Final Score of 2 (green color) and the message 'Investigate and change immediately'.

\section{Discussion}

The analysis of the most common position clearly indicates the impact on the pathological changes of the lumbosacral region of the spine. An ergonomic analysis of our solution indicates the benefit of a favorable position, both on the lumbosacral part of the spine and on the reduction of intrabdominal pressure, which also has the benefit of overall health status. This analysis indicates the need for an adequate working environment that would preserve the patient's health status, as well improve quality of work output. The focus should also be placed on intermittent exercises and rising from a sitting position, which will further improve the patient's health status.

Ergonomic analysis has benefits in a real environment. Chau et al. in their sample indicated that $42 \%$ of men and $47 \%$ of women spend an average of 6.3 of their 8 -hour shifts in sedentary and sitting jobs having problems with the musculoskeletal system [14]. Cramer et al. state that habitual postural patterns are associated with musculoskeletal pathology, and that correcting this position leads to improved clinical presentation [15]. Lis et al. state that low back pain is associated with awkward posture [16]. With development of technology, this problem will be bigger and bigger, and it will surely will get epidemic rate [17]. The imperative must be on prevention. Successful management of occupational musculoskeletal pathology in in improving workplace conditions (ergonomics and work practices), psychosocial factors, diagnostic uncertainties, and the need for active modalities (exercises and a progressive increase in activities of daily living), rather than passive (bed rest and traction) [18].

Strengthening of the abdominal muscles is an additional effective modality that would also lead to the strengthening of the lumbosacral part of the spine. Even in acute pain, treatment should not be exclusively medicamentous, and identification of ethiological causes should be aim of diagnostic approach. Ergonomic analyzes highlight the importance of an adequate working environment and adequate equipment. Although more adequate solutions are more expensive, the long-term benefit is immeasurable..

\section{Conclusion}

A change in body position will decrease lumbar moment and the load on the lumbosacral region of the spine. Work chair with lumbar support, the right desk height, setting the appropriate position of the monitor, selecting the optimal keyboard and mouse, dividing the workspace into appropriate zones, as well as changing lifestyle and habits should be part of the management of people who spend most of their working time in a sitting position.

\section{References}

[1] M. Allegri, S. Montella, F. Salici, A. Valente, M. Marchesini, C. Compagnone et al., "Mechanisms of low back pain: a guide for diagnosis and therapy", Version 2. F1000Res. 2016 Jun 28 [revised 2016 Oct 11];5. pii: F1000 Faculty Rev-1530.

[2] T. Ribeiro, F. Serranheira, H. Loureiro, "Work related musculoskeletal disorders in primary health care nurses", Applied Nursing Research, vol. 33, pp. 72-77, 2017.

[3] M. McDonald, D. B. M. daCosta, S. Ullman, "Musculoskeletal pain in the workforce: the effects of back, arthritis, and fibromyalgia pain on quality of life and work productivity", $J$ Occup Environ Med, vol. 53, no.7, pp. 765-770, 2011.

[4] B. Evanoff, M. A. Dale, A. A. Descatha, "Conceptual Model On Musculoskeletal Disorders For Occupational Healt h Practitioners”, Int J Occup Med Environ Health, vol. 27, no. 1, pp. 145-148, 2014. 
[5] B. R. Da Costa, E. R. Vieira, "Risk factors for work-related musculoskeletal disorders: a systematic review of recent longitudinal studies", American Journal of Industrial Medicine, vol. 53, no. 2, pp. 285-323, 2010.

[6] T. S. Church, D. M. Thomas, C. Tudor-Locke, P. T. Katzmarzyk, C. P. Earnest, R. Q. Rodarte, C. K. Martin, S. N. Blair, C. Bouchard, "Trends over 5 decades in US occupation-related physical activity and their associations with obesity", PLoS One, vol. 6., pp. 19657, 2011.

[7] H. Daneshmandi, A. Choobineh, H. Ghaem, M. Karimi, "Adverse effects of prolonged sitting behavior on the general health of office workers", J Lifestyle Med, vol. 7, pp. 69-75, 2017.

[8] K. M. Diaz, V. J. Howard, B. Hutto, N. Colabianchi, J. E. Vena, M. M. Safford, et al., "Patterns of sedentary behavior and mortality in U.S. middle-aged and older adults: a national cohort study", Ann Intern Med, vol. 167, pp. 465-475, 2017.

[9] J. Salmon, N. Owen, D. Crawford, A. Bauman, J. F. Sallis, "Physical activity and sedentary behavior: a population-based study of barriers, enjoyment, and preference", Health Psychol., vol. 22, pp. 178-188, 2003.

[10] V. Magnon, F. Dutheil, C. Auxiette, "Sedentariness: A Need for a Definition”, Front Public Health. vol. 6, pp. 372, 2018.

[11] N. P. Pronk, A. S. Katz, M. A. Lowry, J. R. Payfer, "Reducing Occupational Sitting Time and Improving Worker Health: The Take-a-Stand Project, 2011”, Prev Chronic Dis, vol. 9, E154, 2012.

[12] T. Borhany, E. Shahid, E. A. Siddique, H. Ali, "Musculoskeletal problems in frequent computer and internet users", J Family Med Prim Care, vol. 7, no. 2, pp. 337-339, 2018.

[13] P. Mairiaux, P. Davis, D. Stubbs, D. Baty, "Relation between intra-abdominal pressure and lumbar moments when lifting weights in the erect posture", Ergonomics, vol. 27, no. 8, pp. 883-894, 1984.

[14] J. Y. Chau, H. P. van der Ploeg, D. Merom, T. Chey, A. E. Bauman, "Cross-sectional associations between occupational and leisure-time sitting, physical activity and obesity in working adults", Prev Med., vol. 195, pp. 195-200, 2012.

[15] H. Cramer, W. E. Mehling, F. J. Saha, G. Dobos, R. Lauche, "Postural awareness and its relation to pain: validation of an innovative instrument measuring awareness of body posture in patients with chronic pain", BMC Musculoskelet Disord., vol. 19, no. 1, pp. 109, 2018.

[16] A. M. Lis, K. M. Black, H. Korn, M. Nordin, "Association between sitting and occupational LBP”, Eur Spine J., vol. 16, no. 2, pp. 283-298, 2007.

[17] G. Li, C. M. Haslegrave, "Seated postures for manual, visual and combined tasks", Ergonomics, vol. 42, no. 8, pp. 1060-1086, 1999.

[18] W. F. Peate, "Occupational musculoskeletal disorders", Primary Care, vol. 21, no. 2, pp. 313-327, 1994. 